\title{
STRATEGI BHABINKAMTIBMAS DALAM UPAYA OPTIMALISASI PENERAPAN PROGRAM DOOR TO DOOR SYSTEM (Studi Kasus Polsek Menganti)
}

\author{
Ramadhan N. \\ ramadhan.n.s.h.s.i.k@pasca.unair.ac.id \\ Program Studi Kajian Ilmu Kepolisian \\ Sekolah Pascasarjana Universitas Airlangga \\ Jln. Airlangga No.4-6 Surabaya
}

\begin{abstract}
The situation of security and public order is highly expected by the entire community to be realized, thus giving rise to a sense of peace and peace for every community and can increase motivation and enthusiasm for work. Implementation of the Community Policing Program in the midst of the community was carried out by the Police in Gresik. The purpose of this study was to analyze the Bhabinkamtibmas strategy in an effort to optimize the application of door to door system programs. The research method used is a qualitative approach, which uses data collection techniques in the form of interviews, observation and documentation. The results of the study indicate that the community Policing strategy in an effort to optimize the implementation of the door-to-door system program is by rolling out personnel from one village to another; do various door to door system activities; attach police aid stickers to the homes of community leaders; empowerment of local wisdom, as well as the vigorous socialization of police of community partners to eliminate the image of the military police.
\end{abstract}

Keywords: Optimization; Community Police; Door to Door System

\begin{abstract}
Situasi keamanan dan ketertiban umum sangat diharapkan oleh seluruh masyarakat untuk terwujud, sehingga menimbulkan rasa damai dan damai bagi setiap komunitas dan dapat meningkatkan motivasi dan antusiasme untuk bekerja. Implementasi Program Pemolisian Masyarakat di tengah-tengah masyarakat dilakukan oleh Kepolisian di Gresik. Tujuan dari penelitian ini adalah untuk menganalisis strategi Bhabinkamtibmas dalam upaya untuk mengoptimalkan penerapan program sistem pintu ke pintu. Metode penelitian yang digunakan adalah pendekatan kualitatif, yang menggunakan teknik pengumpulan data dalam bentuk wawancara, observasi dan dokumentasi. Hasil penelitian menunjukkan bahwa strategi Pemolisian masyarakat dalam upaya untuk mengoptimalkan pelaksanaan program sistem pintu-ke-pintu adalah dengan meluncurkan personel dari satu desa ke desa lain; melakukan berbagai kegiatan sistem pintu ke pintu; menempelkan stiker bantuan polisi ke rumah-rumah para pemimpin masyarakat; pemberdayaan kearifan lokal, serta sosialisasi yang kuat dari polisi dari mitra masyarakat untuk menghilangkan citra polisi militer.
\end{abstract}

Kata kunci: Optimasi; Polisi Masyarakat; Sistem Pintu ke Pintu 


\section{A. Pendahuluan}

Kepolisian Republik Indonesia (Polri) merupakan institusi yang bertanggung jawab di dalam mengupayakan, mencegah, dan mengelimininasi dari setiap gejala yang mungkin muncul dan dapat mengganggu keamanan dan ketertiban di masyarakat. ${ }^{1}$ Polri tentunya memiliki tugas yang cukup berat dalam pencegahan terjadinya pelanggaran, kejahatan, pelayanan masyarakat, dan melindungi serta menertibkan masyarakat.

Tugas pokok Kepolisian Negara Republik Indonesia adalah: (a) memelihara keamanan dan ketertiban masyarakat; (b) menegakkan hukum; dan (c) memberikan perlindungan, pengayoman, dan pelayanan kepada masyarakat. ${ }^{2}$ Terlebih lagi terhadap wilayah-wilayah yang memiliki potensi tingkat kejahatan tinggi seperti wilayah perkotaan atau tingkat Kabupaten.

Kabupaten Gresik merupakan kawasan yang berpotensi berkembang pesat dalam konstelansi Surabaya Metropolitan Area. Posisi Strategis Kabupaten Gresik terlihat dalam Peraturan Pemerintah Nomor 26 Tahun 2010 tentang Rencana Tata Ruang Wilayah Nasional (RTRWN) dan Peraturan Daerah Provinsi Jawa Timur Nomor 5 Tahun 2012 tentang Rencana Tata Ruang Wilayah Provinsi Jawa Timur 2011-2031 dimana Kawasan perkotaan yang diarahkan sebagai Pusat Kegiatan Nasional di Provinsi Jawa Timur adalah Kawasan Perkotaan Gerbangkertosusila (GresikBangkalan- Mojokerto-Surabaya-Sidoarjo-Lamongan). Akibatnya, keadaan wilayah Kabupaten Gresik sendiri rawan dan berpotensi memiliki tingkat kejahatan yang tinggi dan kompleks karena dekat dengan daerah-daerah strategis di Propinsi Jawa Timur. ${ }^{3}$ Salah satu langkah Polres Gresik dalam memberikan suasana Kamtibmas pada masyarakat adalah memberlakukan Program Polmas. Pada studi empiris Cheurprakobit, (2002) mengemukakan bahwa Polmas adalah suatu kegiatan untuk mengajak masyarakat melalui kemitraan antara anggota Polri dan masyarakat, sehingga mampu mendeteksi dan mengidentifikasi permasalahan keamanan di lingkungan serta menemukan pemecahan masalahnya. Polmas merupakan suatu definisi baru untuk aktivitas polisi agar lebih berbeda dari definisi lamanya yang terkesan militeris dan kaku, atau dengan kata lain polmas adalah bentuk pembaharuan aktifitas dan strategi dalam perpolisian. ${ }^{4}$

Bhabinkamtibmas adalah anggota kepolisian yang ditunjuk selaku pembina keamanan dan ketertiban masyarakat. Tujuan yang ingin dicapai dalam kegiatan Bhabinkamtibmas adalah terwujudnya situasi kamtibmas yang mantap dan dinamis dalam rangka mengamankan dan menyukseskan pembangunan nasional. ${ }^{5}$ Sedangkan yang dimaksud dengan kamtibmas adalah suatu kondisi dinamis masyarakat yang ditandai oleh terjaminnya tertib dan tegaknya hukum serta

1 Wahyurudhanto, A. (2018). Efektivitas Pelaksanaan Program Kerjasama Polri dengan JICA di Bidang Polmas. Jurnal Ilmu Kepolisian, Volume 12, Nomor 1 April, 46-61. 


\footnotetext{
2 Undang-Undang Nomor 2 Tahun 2002 tentang Kepolisian Negara Republik

Indonesia, Pasal 13.

${ }^{3}$ Intel Dasar Kabupaten Gresik, 2017

${ }^{4}$ Cheurprakobit, S. (2002). Community policing: Training, Definitions and policy Implication. Policing: An International Journal of Police Strategies \& Management, Vo. 25, No. 4, 709-725.

${ }^{5}$ Azhari, C. A. (2018). Strategi Mengenal Khalayak Bhabinkamtibmas (Bhayangkara Pembinaan Keamanaan dan Ketertiban Masyarakat) Polsekta Samarinda Utara dalam Membangun Kemitraan dengan Masyarakat di Kelurahan Mugirejo. eJournal Ilmu Komunikasi, 6(1), 128-142.
}

terbinanya ketentraman yang mengandung kemampuan membina serta mengembangkan potensi dan kekuatan masyarakat dalam menangkal, mencegah dan menanggulangi segala bentuk pelanggaran hukum dan bentuk-bentuk gangguan lainnya yang dapat meresahkan masyarakat, yang merupakan salah satu prasyarat terselenggaranya proses pembangunan nasional.Bhabinkamtibmas memiliki fungsi dan peran sangat strategis dalam mewujudkan kemitraan polisi dengan masyarakat, sehingga secara bersama- sama mampu mendeteksi gejala yang dapat menimbulkan problema pada masyarakat, juga mampu mendapatkan solusi untuk mengantisipasi problema serta mampu memelihara keamanan dan ketertiban masyarakat. ${ }^{6}$ Berbagai upaya diarahkan untuk mengoptimalkan kinerja Polres Gresik, termasuk pembekalan kepada Bhabinkamtibmas di Polsek-Polsek wilayah hukum Polres Gresik, salah satunya di wilayah Kecamatan Menganti.

Kecamatan Menganti sendiri memiliki luas wilayah 6.734.400 Ha, dengan wilayah administrasi Pemerintahan terdiri dari Desa 22, Dusun 75, Rukun Warga (RW), 149 dan Rukun Tetangga ( RT ) sebanyak 454 RT. Hal ini berarti membutuhkan anggota kepolisian yang dapat melakukan pembinaan keamanan dan ketertiban masyarakat yang maksimal, yaitu Bhabinkamtibmas itu sendiri. ${ }^{7}$

Dengan demikian dengan adanya Bhabinkamtibmas, Polri dalam hal ini harus mampu membangun interaksi sosial yang erat dan mesra dengan masyarakat, yaitu keberadaannya menjadi simbol persahabatan antara warga masyarakat dengan polisi dengan mengedepankan dan memahami kebutuhan adanya rasa aman warga masyarakat, yang lebih mengedepankan tindakan pencegahan kejahatan (crime prevention).

Berbagai cara telah dilaksanakan untuk merubah paradigma masyarakat mengenai citra kaku Bhabinkamtibmas salah satunya dengan kegiatan/program door to door system. Kegiatan DDS (Door to Door System) merupakan kegiatan wajib yang berupa mengunjungi rumah-rumah masyarakat, menghadiri kegiatan-kegiatan masyarakat seperti gotong royong, dan penyuluhan ke area tempat-tempat seperti sekolah, kantor, maupun tempat hiburan yang berada dilingkungan Bhabinkamtibmas itu sendiri. Berikut adalah rekap banyaknya jumlah kegiatan yang dilakukan Polsek Menganti selama November-Desember 2018. 
Wilayah hukum Polres Gresik sendiri, masih sering berpotensi muncul gejolak di masyarakat secara tiba-tiba yang bisa saja tidak dapat diantisipasi sebelumnya di tingkat Polsek, dan masih banyak penanganan masalah Kamtibmas yang harus dilakukan di tingkat Polres karena Polsek tidak mampu menangani kendati masalah tersebut sebenarnya bisa diselesaikan di tingkat Polsek.

\footnotetext{
${ }^{6}$ Keputusan Kapolri Nomor: KEP/773NII/2011, tanggal 29 Juli 2016 Tentang Buku Pintar Bhabinkamtibmas.

${ }^{7}$ Intel Dasar Polsek Menganti, 2017
}

Melihat paparan di atas, pada penelitian ini akan fokus pada Strategi Polmas Bhabinkamtibmas dalam Optimalisasi Penerapan Program Door to Door System (Studi Kasus di Polsek Menganti). Beberapa hal yang sering diantisipasi oleh Bahbinkamtibmas Polres Gresik adalah banyak berita bohong (hoax), peredaran miras oplosan, perjudian, penyalahgunaan narkoba, dan tawuran antar warga sehingga menimbulkan kecemasan yang tidak perlu, kemudian isu-isu radikalisme yang dapat meresahkan masyarakat Gresik, khusunya di Kecamatan Menganti. Oleh karena itu, dibutuhkan strategi yang optimal untuk melaksanakan kegiatan door to door system sebagai bentuk pendekatan serta pembinaan kepada masyarakat, agar menjadi mitra kepolisian dalam menciptakan keamanan dan ketertiban masyarakat tersebut.

\section{B. Metode}

Metode penelitian yang digunakan adalah pendekatan kualitatif, dimana menggunakan teknik pengumpulan data berupa wawancara, observasi dan dokumentasi. Informan dalam penelitian yaitu anggota Bhabinkamtibmas, Tokoh Masyarakat dan Masyarakat di wilayah hukum Polres Gresik, khususnya di wilayah hukum Polsek Menganti.

\section{Pembahasan}

\section{Pelaksanaan Program Door To Door System Di Wilayah Hukum} Polsek Menganti

\subsection{Gambaran Kondisi Bhabinkamtibmas Polsek Menganti dalam Penerapan Program Door to Door System Saat Ini}

Door to Door System merupakan suatu kegiatan yang dilaksanakan secara nyata (real) oleh setiap anggota Kepolisian Republik Indonesia (Polri), dalam mengunjungi tempat tinggal, tempat ibadah, sekolah, perkantoran, tempat perbelanjaan dan lain-lainnya dengan berkomunikasi secara langsung dengan orang yang dikunjungi serta mendata keterangan dan informasi dari orang tersebut sesuai dengan contoh blangko kunjungan. Agar kegiatan kunjungan 
tersbut lebih nyata (real), maka perlu dilakukan dokumentasi atau pengambilan gambar/ foto dari kegiatan tersebut sebagai bukti dari kegiatan kunjungan dan juga sebagai laporan kepada pimpinan. Sementara itu, kondisi Bhabinkamtibmas di Polsek Menganti saat ini dapat dijelaskan sebagai berikut:

\section{a. Kuantitas Bhabinkamtibmas di Polsek Menganti}

Jumlah Bhabinkamtibmas sebanyak 22 personel pada tahun 2018. Hingga sekarang ini jumlah Bhabinkamtibmas telah memenuhi harapan dan kebijakan dari Pimpinan Polsek Menganti. Namun demikian jumlah personel yang menjabat sebagai seorang Bhabinkamtibmas sudah didukung dengan personel perwira yang mendukung pengendalian kegiatan Bhabinkamtibmas di lapangan. Personel yang berpangkat Perwira diharapkan ada disetiap Polsek karena dapat menjadi penggerak perencanaan, pengorganisasian, pelaksanaan, pengendalian dan pengawasan setiap program yang dilaksanakan terdepan di Polsek dapat berjalan maksimal.

b. Kualitas Bhabinkamtibmas di Polsek Menganti Bhabinkamtibmas yang telah memiliki Skep Bhabinkamtibmas dan pendidikan pengembangan (Dikbang) tergambar pada uraian dibawah, dimana jumlah personel Bhabinkamtibmas sebanyak 22 personel yang telah memiliki Skep Bhabinkamtibmas baru 7 (tujuh) personel yang telah memiliki

Dikbang sesuai tugas Bhabinkamtibmas.

\section{c. Dukungan Anggaran}

Dukungan anggaran sama halnya seperti dukungan Sumber Daya Manusia (SDM) yang tidak bisa disisihkan dalam kegiatan Bhabinkamtibmas Gresik.

\section{d. Dukungan Sarana dan Prasarana}

Sarana dan prasarana sangat mempengaruhi keberhasilan kegiatan Bhabinkamtibmas di lapangan. Kemampuan perorangan Bhabinkamtibmas akan lebih maksimal apabila sarana dan prasarana yang dibutuhkan tercukupi.

\subsection{Faktor-Faktor yang Mempengaruhi Penerapan Program Door to Door System di Polsek}

\section{Menganti}

\subsubsection{Faktor Pendukung}

a. Adanya dukungan SOP yang mengatur sinergi Bhabinkamtibmas tingkat Polres dan Polsek. Standart operational procedure (SOP) merupakan syarat penting dalam melakukan suatu aktifitas atau kinerja pada bidang-bidang khusus. Adanya SOP menjadi ukuran perencanaan terhadap penerapan suatu program, hal ini juga termasuk program door to door system. 
b. Dukungan Pemerintah Setempat dan Tokoh Masyarakat terhadap Keamanan dan Ketertiban Masyarakat sangat Tinggi

Kerjasama antara divisi/ unit organisasi yang melaksanakan program door to door system, telah membuka peluang bagi Kepolisian untuk mengembangkan kebijakan lokal secara bijaksana.

\section{c. Penyelesaian Masalah dengan Mediasi}

Untuk mengantisipasi tantangan dan ancaman tersebut diatas, Polri telah menyiapkan beberapa kebijakan dan strategi bertindak yaitu melalui proactive policing (pencegahan sebelum gangguan kamtibmas) dengan meningkatkan kegiatan deteksi dini dan deteksi aksi dengan meningkatkan kegiatan pemolisian masyarakat (polmas) melalui problem solving, menumbuhkan kesadaran, kepatuhan dan ketaatan hukum dengan meningkatkan kegiatan pencegahan terhadap berbagai bentuk tindakan intoleransi dan paham radikal pro kekerasan agar tidak meluas dan mengoyak persatuan dan kesatuan.

d. Dukungan dan harapan masyarakat terhadap kehadiran Polri Meningkat

Penerapan door to door system sangat didukung oleh masyarakat, karena dianggap mewakili komitmen masyarakat dalam ikut aktif berkontribusi dalam menjaga keamanan dan ketertiban wilayahnya.

\subsubsection{Faktor Penghambat}

a. Kurangnya Kuantitas Personel yang Mengakibatkan Rangkap Jabatan

Seperti yang telah dijelaskan, bahwa jumlah personel Bhabinkamtibmas hanya 22 personel di wilayah hukum Polsek Menganti, dengan wilayah yang cukup banyak penduduk sebanyak 122.560 jiwa terdiri dari laki-laki 62.158 jiwa, perempuan 60.402 jiwa, sehingga, jumlah 22 personel dinilai sangat kurang memadai.

b. Kualitas SDM Menurun karena Personel Banyak yang Paruh Baya

Membahas mengenai kualitas sumber daya manusia Bhabinkamtibmas di Polsek Menganti, kemudian diketahui bahwa faktor yang menghambat penerapan door to door system salah satunya adalah personel bhabinkamtibmas banyak yang dalam usia paruh baya, sehingga kinerja mengalami penurunan.

c. Kemampuan komunikasi anggota kurang baik

Komunikasi adalah salah satu cara untuk melakukan interaksi dengan seseorang, dimana merupakan salah satu hal yang paling penting dalam penerapan program door to door system di wilayah hukum Polsek Menganti.

d. Kurangnya Pengetahuan Informasi Terbaru mengenai Gangguan Keamanan dan 


\section{Ketertiban}

Seiring perkembangan teknologi dan peradaban manusia, pada umumnya akan meningkat pula gangguan keamanan dan ketertiban dalam suatu tatanan masyarakat. Sehingga, perlu pengetahuan yang baik mengenai perkembangan informasi terbaru terkait gangguan tersebut.

\section{Strategi Bhabinkamtibmas polsek Menganti Dalam Optimalisasi Penerapan Program}

\section{Door To Door}

\subsection{Melakukan model Rolling Personel Bhabinkamtibmas}

Pada pelaksanaannya, Polsek Menganti melakukan program door to door system berdasarkan prinsip satu bhabin satu desa. Hal ini berarti satu personel bhabinkamtibmas bertanggungjawab atas satu desa. Namun, setelah terjadi beberapa kasus yang menyebabkan keresahan warga di wilayah Polsek Menganti meningkat, maka pola tersebut diubah dengan pergantian tanggungjawab oleh personel. Dengan dilakukan rolling (pergantian personel dari satu desa ke desa lain), dengan tujuan adanya pembaharuan analisis kasus oleh personel, dan dapat menciptakan kepercayaan antar tokoh masyarakat dengan anggota Polsek Menganti.

\subsection{Melakukan Ragam Kegiatan door to Door System berupa Binluh, Sambang dan}

\section{Anjangsana}

Ragam kegiatan door to door system di Polsek Menganti cukup bervariasi, dimana terkait dengan binluh (bimbingan dan penyuluhan), kemudian sambaing, dan anjangsana. Binluh digunakan untuk melakukan bina masyarakat melalui kegiatan warga, sementara samban dan anjangsana merupakan kegiatan datang ke rumah warga dan tokoh masyarakat secara satu persatu. Berikut merupakan bebera contoh ragam kegiatan Polsek Menganti yaitu dalam binluh, sambang dan anjangsana.

\begin{tabular}{|l|l|l|l|l|}
\hline Kegiatan & Sasaran & \multicolumn{1}{|c|}{ Waktu } & $\begin{array}{c}\text { Penanggun } \\
\text { g jawab }\end{array}$ & \multicolumn{1}{|c|}{ Hasil yang dicapai } \\
\hline Binluh & $\begin{array}{l}\text { Para Tokoh } \\
\text { Agama Ds, } \\
\text { Bringka ng }\end{array}$ & $08.00-09.00$ & $\begin{array}{l}\text { Kanit } \\
\text { Binmas }\end{array}$ & $\begin{array}{l}\text { Para Tokoh Agama } \\
\text { lainnya mendukung } \\
\text { dalam menjaga }\end{array}$ \\
& & & & $\begin{array}{l}\text { Harkamtibmas serta tidak } \\
\text { mudah percaya tentang } \\
\text { adanya berita - berita }\end{array}$ \\
& & & $\begin{array}{l}\text { Hoax yang sengaja } \\
\text { disebarkan luaskan di } \\
\text { Media social terkait } \\
\text { issu mengadu domba } \\
\text { antar umat beragama }\end{array}$ \\
\hline
\end{tabular}




\begin{tabular}{|c|c|c|c|c|}
\hline Sambang & $\begin{array}{l}\text { Tokoh } \\
\text { Masyara } \\
\text { kat Ds. } \\
\text { Bringka ng }\end{array}$ & $\begin{array}{l}09.00-10.00 \\
\text { wib }\end{array}$ & $\begin{array}{l}\text { Kanit } \\
\text { Binmas }\end{array}$ & $\begin{array}{l}\text { Para Tokoh Masyarakat } \\
\text { mendukung Polri dalam } \\
\text { menjaga Harkamtibmas } \\
\text { serta tidak mudah } \\
\text { percaya tentang adanya } \\
\text { berita Hoax yang } \\
\text { sengaja } \\
\text { disebarkanluaskan di } \\
\text { Media social terkait } \\
\text { Pilnres dan nileo } 2010\end{array}$ \\
\hline $\begin{array}{l}\text { Anjang- } \\
\text { sana }\end{array}$ & $\begin{array}{l}\text { Tokoh } \\
\text { Masyara kat } \\
\text { Ds. } \\
\text { Bringka } \\
\text { ng }\end{array}$ & $\begin{array}{ll}10.00 & - \\
11.00 \mathrm{wib}\end{array}$ & $\begin{array}{l}\text { Kanit } \\
\text { Binmas }\end{array}$ & $\begin{array}{l}\text { Para Tokoh Masyarakat } \\
\text { mendukung Polri } \\
\text { dalam menjaga } \\
\text { Harkamtibmas } \\
\text { serta tidak mudah percaya } \\
\text { tentang adanya berita } \\
\text { Hoax yang sengaja } \\
\text { disebarkan luaskan di } \\
\text { Media social terkait }\end{array}$ \\
\hline
\end{tabular}

Sementara itu, dapat juga ditampilkan dalam dokumentasi sebagai berikut:

\section{Gambar 1:}

\section{Kegiatan Sambang dan Binluh di Desa Bringkang, Menganti}

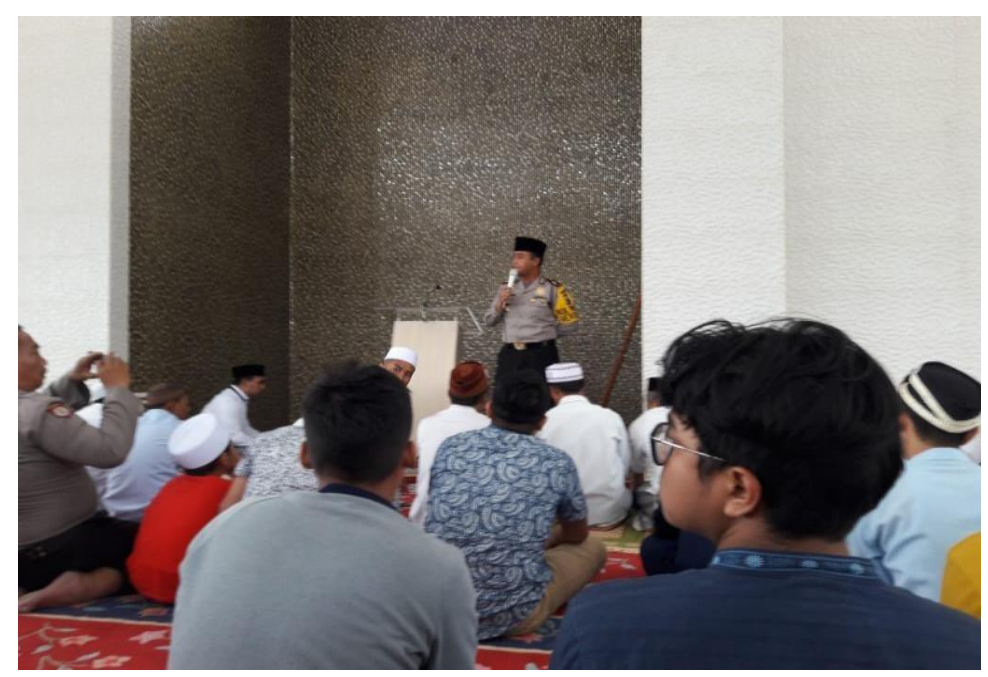

Sumber: Dokumentasi Polsek Menganti, 2018

\subsection{Menempelkan Stiker Bantuan Polisi}

Stiker seringkali digunakan untuk memberi informasi singkat mengenai suatu hal, dalam hal ini pihak Polsek Menganti menggunakan 
stiker untuk memberi informasi nomor telpon bantuan yang digunakan menghubungi petugas setempat dalam upaya pencegahan dan penyelesaian poetnsi gangguan keamanan dan ketertiban di masyarakat. Untuk memberi informasi mengenai bantuan polisi, saat mengunjungi rumah ke rumah atau di tokoh masyarakat, kami memberi stiker yang berisi nomor telpon bantuan polisi, yangmana dapat dihubungi saat melihat adanya ancaman gangguan keamanan dan ketertiban di masyarakat.

Kegunaan stiker adalah memberi informasi melalui tuturan di dalamnya. Stiker juga merupakan salah satu media komunikasi yang banyak digunakan dalam berkomunikasi pasif. Walaupun tidak banyak informasi yang dapat ditampilkan dalam stiker, media ini banyak diminati. Pada zaman modern ini para pengguna stiker tidak hanya mengunakan stiker sebagai pemanis belaka. Bahan dan jenis stiker beragam tergantung pada tujuan dari pembuatan stiker tersebut. Ada yang menggunakan untuk memperindah suatu tampilan, untuk media promosi, member petunjuk, dan tidak sedikit pengguna stiker memasang stiker sebagai penunjuk identitas.

\subsection{Pemberdayaan Kearifan Lokal Berupa Rasa Kekerabatan yang}

\section{Erat}

Berbagai kerawanan yang dapat menghambat tercapainya keamanan dan ketertiban masyarakat harus dapat ditangani dengan memanfaatkan potensi positif dinamis yang ada dalam masyarakat secara terpadu. Terdapat beberapa langkah yang digunakan Kepolisian untuk mendeteksi potensi kearifan lokal lain yaitu dengan cara:

(1) Kapolres memerintahkan Kasat dan Kanit Binmas Polsek untuk membuat rencana latihan peningkatan pengetahuan anggota

Bhabinkamtibmas

(2) Kapolres memerintahkan Kasat dan Kanit Binmas untuk menghubungi dan menjalin kerjasama dengan tokoh-tokoh masyarakat serta perangkat desa setempat untuk bisa

memberikan materi ilmu pengetahuan sosial, dan mencari tahu media-media apa saja yang dapat digunakan untuk melakukan pendekatan dan mempererat ikatan dengan masyarakat di desa setempat.

(3) Kapolres memerintahkan Kasat dan Kanit Binmas untuk membuat buku saku untuk para anggota Bhabinkamtibmas sebagai acuan singkat dalam pelaksanaan tugas di lapangan bagi para bhabin. 
(4) Kasat dan Kanit Binmas memerintahkan anggota Bhabin untuk merangkum buku-buku terkait pengetahuan mengenai sejarah lisan dan budaya Polsek Menganti kemudian hal-hal mengenai tupoksi Bhabinkamtibmas dalam bentuk perpustakaan sederhana.

\subsection{Adanya Giat Sosialisasi Polisi Mitra Warga untuk \\ Menghilangkan Citra Militer Polisi}

Door to Door System merupakan suatu kegiatan yang dilaksanakan secara nyata (real) oleh setiap anggota Kepolisian Republik Indonesia (Polri), dalam mengunjungi tempat tinggal, tempat ibadah, sekolah, perkantoran, tempat perbelanjaan dan lain-lainnya dengan berkomunikasi secara langsung dengan orang yang dikunjungi serta mendata keterangan dan informasi dari orang tersebut sesuai dengan contoh blangko kunjungan.

Polri dalam kamtibmas bermaksud harus memposisikan diri sebagai mitra kerja masyarakat yang menjadi aktualisasi dari tugas

Polisi di tengah-tengah masyarakat dalam menciptakan keamanan, sesuai dengan dasar pembentukan bhabinkamtibmas itu sendiri, yaitu untuk membangun kemitraan dengan masyarakat, dengan cara membentuk kesadaran masyarakat akan keamanan dan ketertiban, tidak bisa tergantung pada Polisi, tapi juga dilakukan oleh mereka sendiri.

Pada dasarnya mewujudkan hubungan polisi dengan masyarakat yang ideal bukanlah merupakan hal yang mudah. Ada yang berproses sangat cepat dan ada juga yang lambat. Namun yang lebih penting adalah bagaimana polisi bersama-sama dengan segenap komponen masyarakat mampu mencegah terjadinya berbagai bentuk kejahatan, dengan memperoleh dukungan dari masyarakat secara maksimal. Untuk itu upaya mencegah kejahatan yang dilakukan oleh kepolisian bersama dengan warga masyarakat harus dapat menimbulkan efek pencegahan terhadap muncul dan berkembangnya kejahatan selanjutnya.

Fungsi-fungsi pembinaan keamanan dan ketertiban masyarakat (Kamtibmas) melalui antara lain adalah seperti peran Binmas (Pembina Masyarakat), kemudian Binmas dengan Kamtibmas swakarsa, selanjutnya membentuk Babinkamtibmas (Bintara Pembina Keamanan dan Ketertiban Masyarakat) yang diharapkan sebagai ujung tombak polisi dalam membina masyarakat untuk melaksanakan program-progam Kamtibmas yang telah digariskan oleh Polri maupun pemerintah. Sesuai dengan paradigma kepolisian sipil dalam masyarakat madani seperti sekarang ini, maka gaya perpolisian yang diterapkan pun harus berubah menuju polisi yang demokratis, mau mendengar dan menerima apa yang menjadi kehendak masyarakat. Dalam menghadapi persoalan yang ada warga masyarakat sendiri yang 
menentukan dan mengambil keputusan dalam menangani masalah-masalah sosial dan keamanan dilingkungannya. Polisi lebih berfungsi sebagai fasilitator, narasumber dan pengendali terhadap penyimpangan hukum dalam pelaksanaannya.

\section{Kesimpulan}

1. Evaluasi terhadap penerapan program door to door system di wilayah hukum Polsek Menganti saat ini adalah Gambaran kondisi

Bhabinkamtibmas Polsek Menganti dalam penerapan program door to door system saat ini yaitu, Jumlah Bhabinkamtibmas sebanyak 22 personel pada tahun 2018. Dari 22 personel Bhabinkamtibmas, yang telah memiliki Dikbang (pendidikan pengembangan) baru 7 personel, sementara yang lain berasal dari rangkap jabatan yang berbeda, seperti dari lantas, reskrim dan lainnya, sehingga kualitas anggota Bhabinkamtibmas masih ada yang belum memenuhi tingkat kompetensi sebagai Bhabinkamtibmas. Dukungan anggaran sudah diterima dari Polres, sayangnya rincian anggaran masih kurang maksimal, karena belum teranggarkannya biayabiaya kegiatan pelayanan Bhabinkamtibmas kepada masyarakat, biaya-biaya penambahan sarana prasarana pendukung tugas dan biaya-biaya pemeliharaan sarana prasarana yang diperlukan. Sarana dan prasarana belum sepenuhnya mendukung penerapan program door to door system di wilkum Polsek Menganti. Sementara itu, faktor-faktor yang mempengaruhi penerapan program door to door system di wilkum Polsek Menganti terdapat faktor pendukung dan faktor penghambat.

2. Strategi Polmas Bhabinkamtibmas dalam upaya optimalisasi penerapan program door to door system adalah dengan melakukan model rolling personel bhabinkamtibmas dari satu desa ke desa yang lain; melakukan ragam kegiatan door to door system berupa binluh, sambang dan anjangsana; menempelkan stiker bantuan polisi di rumah tokoh-tokoh masyarakat; pemberdayaan kearifan lokal berupa rasa kekerabatan yang erat antar warga dalam rangka mewujudkan keamanan dan ketertiban yang kondusif, serta adanya giat sosialisasi polisi mitra warga untuk menghilangkan citra militer polisi.

\section{Bibliography}

Buku

Azhari, C. A. (2018). Strategi Mengenal Khalayak Bhabinkamtibmas (Bhayangkara Pembinaan Keamanaan dan Ketertiban Masyarakat) Polsekta Samarinda Utara dalam Membangun Kemitraan dengan Masyarakat di Kelurahan Mugirejo. eJournal Ilmu Komunikasi, $6(1)$.

Cheurprakobit, S. (2002). Community policing: Training, Definitions and policy Implication. Policing: An International Journal of Police

Strategies \& Management, Vo. 25, No. 4.

Keputusan Kapolri Nomor: KEP/773NII/2011, tanggal 29 Juli 2016 
Tentang Buku Pintar Bhabinkamtibmas.

Wahyurudhanto, A. (2018). Efektivitas Pelaksanaan Program Kerjasama

Polri dengan JICA di Bidang Polmas. Jurnal Ilmu Kepolisian, Volume 12, Nomor 1 April. 